\title{
Mapping Quantitative Trait Loci for 1000-Grain Weight in a Double Haploid Population of Common Wheat
}

\author{
Tao Liu ${ }^{1,2,+}$, Lijun Wu ${ }^{1,2,+}$, Xiaolong Gan ${ }^{1,2}$, Wenjie Chen ${ }^{1,3}$, Baolong Liu ${ }^{1,3}$, George Fedak ${ }^{4}$, \\ Wenguang Cao ${ }^{4}$, Dawn Chi ${ }^{4}$, Dengcai Liu ${ }^{5}{ }^{-}$, Huaigang Zhang ${ }^{1,2,3, *}$ and Bo Zhang ${ }^{1,3, *}$ \\ 1 Northwest Institute of Plateau Biology, Key Laboratory of Adaptation and Evolution of Plateau Biota (AEPB), \\ Chinese Academy of Sciences, Xining 810008, China; liutao415@mails.ucas.ac.cn (T.L.); \\ wljd126@126.com (L.W.); ganxiaolong16@mails.ucas.ac.cn (X.G.); cwj60905@163.com (W.C.); \\ blliu@nwipb.cas.cn (B.L.) \\ 2 University of Chinese Academy of Sciences, Beijing 100049, China \\ 3 Qinghai Province Key Laboratory of Crop Mol. Breeding, Xining 810008, China \\ 4 Ottawa Research and Development Centre, Agriculture and Agri-Food Canada, 960 Carling Avenue, \\ Ottawa, ON K1A 0C6, Canada; George.Fedak@Canada.ca (G.F.); wenguang.Cao@Canada.ca (W.C.); \\ Dawn.Chi@Canada.ca (D.C.) \\ 5 Triticeae Research Institute, Sichuan Agricultural University, Chengdu 611130, China; dcliu7@yahoo.com \\ * Correspondence: hgzhang@nwipb.cas.cn (H.Z.); zhangbo@nwipb.cas.cn (B.Z.) \\ + These authors contributed equally to this work.
}

Received: 7 April 2020; Accepted: 28 May 2020; Published: 31 May 2020

check for updates

\begin{abstract}
Thousand-grain weight (TGW) is a very important yield trait of crops. In the present study, we performed quantitative trait locus (QTL) analysis of TGW in a doubled haploid population obtained from a cross between the bread wheat cultivar "Superb" and the breeding line "M321" using the wheat 55-k single-nucleotide polymorphism (SNP) genotyping assay. A genetic map containing 15,001 SNP markers spanning 2209.64 cM was constructed, and 9 QTLs were mapped to chromosomes 1A, 2D, 4B, 4D, 5A, 5D, 6A, and 6D based on analyses conducted in six experimental environments during 2015-2017. The effects of the QTLs qTgw.nwipb-4DS and qTgw.nwipb-6AL were shown to be strong and stable in different environments, explaining 15.31-32.43\% and 21.34-29.46\% of the observed phenotypic variance, and they were mapped within genetic distances of $2.609 \mathrm{cM}$ and $5.256 \mathrm{cM}$, respectively. These novel QTLs may be used in marker-assisted selection in wheat high-yield breeding.
\end{abstract}

Keywords: DH population; wheat; QTL analysis; TGW; wheat55k SNP array

\section{Introduction}

Bread wheat is one of the world's major grain crops. Due to an increasing population [1], the development of new high-yielding varieties remains the primary goal of wheat-breeding programs [2]. The final grain yield is a complex trait that is often strongly affected by genetic and environmental factors. In cereal crops, the thousand-grain weight (TGW) is an important yield component, and an increased TGW is key for further increasing the grain yield. In addition, TGW is more stably inherited than the overall final production [3-5].

A genetic map of molecular markers is extremely useful for plant breeding; with an increasing density of molecular markers in genetic maps, a quantitative trait locus (QTL) analysis has been widely used to analyze specific yield-related traits in bread wheat. In recent decades, polymorphic markers such as microsatellite markers [6,7], RAPD (random amplified polymorphic DNA) [8,9], and AFLP 
(amplified fragment length polymorphism) [9] have been used to construct genetic maps. Many major QTLs related to TGW have been mapped to almost all wheat chromosomes, with the exception of 6D. Campbell et al. (1999) identified three QTLs for TGW on chromosomes 1A, 1B, and 7A [10]. Varshney et al. (2000) found multiple QTLs on chromosomes 1A, 1D, 2B, 4B, 5B, 6B, 7A, and 7D controlling TGW [6]. Huang et al. (2003) discovered eight QTLs on chromosomes 2A, 2D, 4D, 5A, 7B, and 7D regulating TGW in a $\mathrm{BC}_{2} \mathrm{~F}_{2}$ population [11]. Two prominent TGW QTLs were detected on chromosomes 3D and 4A in a study by McCartney et al. (2005) [8]. Ramya et al. (2010) detected six QTLs on chromosomes 1A, 2B, 2D, 5A, 5B, and 5D associated with the TGW trait [12]. Other QTLs for TGW have been identified on other chromosomes [5,13-19]. Due to the large size of the wheat genome, the development and application of these markers in wheat are time-consuming and expensive, and the genetic distance between the markers in the maps is relatively large, so map-based gene cloning is difficult to perform [20]. To date, TaGW2-6A and TaFlo2-A1 are the only two genes controlling the grain weight that have been cloned [21,22].

A high-density genetic map is more effective and essential for QTL analysis in cereal crops [23,24]. However, single-nucleotide polymorphisms (SNPs) are the most promising molecular markers [25], showing a high abundance and a uniform distribution throughout the genome, and have been increasingly applied in plants in recent years [26]. Low mutation rates and stable genetics are key characteristics of SNPs. The QTLs obtained from SNPs present a high resolution and can be used for marker-assisted selections to improve selection accuracy and breeding efficiency [27]. With the development of sequencing technology, various wheat SNP array chips have been developed and utilized for QTL analysis, such as the Wheat $9 \mathrm{~K}$, Wheat $90 \mathrm{~K}$, Wheat $660 \mathrm{~K}$, and Wheat $820 \mathrm{~K}$ chips $[23,28-30]$. The Wheat $55 \mathrm{~K}$ chip developed by the Chinese Academy of Agricultural Sciences contains 53,063 SNP markers, which were carefully selected from the Wheat $660 \mathrm{~K}$ array. Liu et al. (2018) constructed a high-density genetic map and identified a novel major QTL for a productive tiller number by using Wheat 55 K SNP array chips [20]. Ren et al. (2018) utilized the Wheat 55 K SNP array to perform a QTL analysis for the tiller number in a wheat recombinant inbred line population and identified $c q T N-2 D .2$ as a major QTL [31]. Compared with other SNP arrays, the Wheat $55 \mathrm{k}$ SNP array is more efficient and lower in cost.

In the present study, nine TGW QTLs, including two major QTLs (qTgw.nwipb-4DS and qTgw.nwipb-6AL) were detected in a doubled haploid (DH) population using a wheat $55 \mathrm{k}$ SNP array and three years of TGW data from three environments on the Qinghai Plateau. The newly detected $q T g w . n w i p b-4 D S$ and $q T g w . n w i p b-6 A L$ loci are expected to be valuable for map-based cloning and wheat improvement.

\section{Results}

\subsection{Genetic Map Construction}

According to the minor allele frequency (frequency $<0.3$ ) and marker polymorphism between the two parents, approximately 18-k SNPs were selected from the Wheat $55 \mathrm{k}$ chip. After filtering the SNPs with missing rates $>10 \%$ and distortion values $<0.01$, a high-density genetic map containing 15,001 SNP markers spanning $2209.64 \mathrm{cM}$ was constructed (Table 1), with an average of $0.147 \mathrm{cM}$ per SNP locus. Among these SNPs, 6876 (45.84\%), 6374 (42.49\%), and 1751 (11.67\%) were mapped to genomes $\mathrm{A}, \mathrm{B}$, and $\mathrm{D}$, respectively (Table $\mathrm{S} 1$ ).

The 15,001 markers were divided into 773 bins, with an average distance of $2.859 \mathrm{cM}$ between two bins, and these bins were mapped to 25 linkage groups for the 21 chromosomes of wheat (Table 1 ). Two linkage groups were constructed for chromosomes 3B, 4D, 5D, and 6D. Among these bins, 263 bins included only one marker, and the largest bins contained 1431 SNPs (Table S2 and Table S3). Most of the bins were distributed on genome A (37.39\%) and genome B (36.22\%), while only $26.39 \%$ of bins were mapped to genome $\mathrm{D}$. The length of the linkage group maps ranged from $13.11 \mathrm{cM}(3 \mathrm{~B}-2)$ to 
$158.98 \mathrm{cM}(3 \mathrm{~A})$. The bin numbers in the maps ranged from 10 to 55 . The average genetic distance between contiguous bin markers ranged from $1.31 \mathrm{cM}$ to $4.72 \mathrm{cM}$.

Table 1. Distribution of the mapped markers in the genetic map. SNP: single-nucleotide polymorphisms.

\begin{tabular}{ccccccc}
\hline \multirow{2}{*}{ Chr. } & Group & Length (cM) & SNP Markers & cM per & Number of & cM per \\
\cline { 5 - 6 } & & & & SNP Marker & Bin Markers & Bin Marker \\
\hline 1A & 1 & 40.11 & 535 & 0.07 & 17 & 2.36 \\
1B & 1 & 95.80 & 726 & 0.13 & 31 & 3.09 \\
1D & 1 & 60.99 & 527 & 0.12 & 16 & 3.81 \\
2A & 1 & 86.71 & 1613 & 0.05 & 32 & 2.71 \\
2B & 1 & 146.21 & 1116 & 0.13 & 52 & 2.81 \\
2D & 1 & 103.72 & 194 & 0.53 & 34 & 3.05 \\
3A & 1 & 158.98 & 897 & 0.18 & 53 & 3.00 \\
3B & 1 & 67.69 & 146 & 0.46 & 33 & 2.05 \\
& 2 & 13.11 & 31 & 0.42 & 10 & 1.31 \\
3D & 1 & 112.02 & 93 & 1.20 & 27 & 4.15 \\
4A & 1 & 110.26 & 650 & 0.17 & 41 & 2.69 \\
4B & 1 & 100.26 & 1496 & 0.07 & 36 & 2.79 \\
4D & 1 & 21.17 & 56 & 0.38 & 10 & 2.12 \\
& 2 & 66.15 & 48 & 1.38 & 14 & 4.72 \\
5A & 1 & 148.47 & 896 & 0.17 & 55 & 2.70 \\
5B & 1 & 92.68 & 549 & 0.17 & 44 & 2.11 \\
5D & 1 & 33.75 & 26 & 1.30 & 10 & 3.38 \\
& 2 & 90.25 & 75 & 1.20 & 33 & 2.73 \\
6A & 1 & 103.75 & 1678 & 0.06 & 48 & 2.16 \\
6B & 1 & 119.78 & 955 & 0.13 & 42 & 2.85 \\
6D & 1 & 31.21 & 14 & 2.23 & 10 & 3.12 \\
& 2 & 67.26 & 89 & 0.76 & 18 & 3.74 \\
7A & 1 & 143.21 & 607 & 0.24 & 43 & 3.33 \\
7B & 1 & 112.93 & 1355 & 0.08 & 32 & 3.53 \\
7D & 1 & 83.17 & 629 & 0.13 & 32 & 2.60 \\
Total & 25 & 2209.64 & 15,001 & 0.15 & 773 & 2.86 \\
\hline
\end{tabular}

The flanking sequences of the SNPs were used for BLAST searches with the IWGSC (International Wheat Genome Sequencing Consortium) refseqv1.0. The order of most of the SNP markers distributed in the present genetic map were consistent with the published wheat genome (Figure 1 and Figure S1). Among 15,001 SNP markers, 1304 SNP markers (8.69\%) showed the best hits to the CDS (coding sequence) of Chinese spring, and these SNPs were considered to be coding-region SNPs (Table S4). 


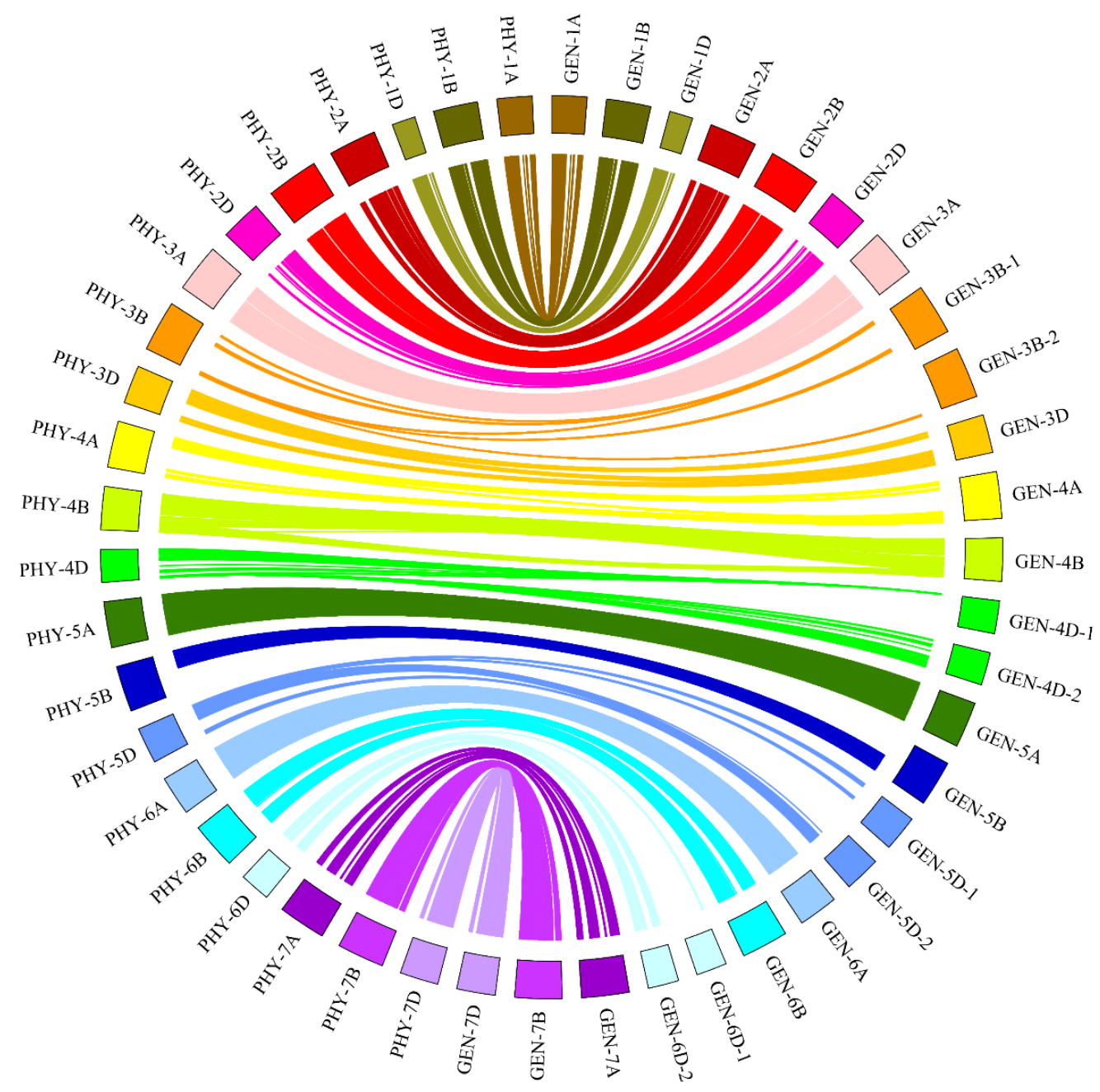

Figure 1. The diagrammatic of the relationship between single-nucleotide polymorphism (SNP) markers in wheat genetic and physical maps. GEN-1A to GEN-7D denote the 25 linkage groups that belong to the 21 chromosomal genetic maps of wheat, and PHY-1A to PHY-7D show the 21 chromosomal physical maps of wheat.

\subsection{Phenotypic Statistical Analysis}

The 1000-grain weight values of Superb and M321 from the six environments were $47.40(\mathrm{~g}) \pm 1.44$ $(\mathrm{g})$ and $38.76(\mathrm{~g}) \pm 1.30(\mathrm{~g})$, respectively, indicating a significant difference in the TGW trait between Superb and M321 (Figure S2 and Table S5). The TGW trait showed an obviously normal distribution in the DH population (Figure S2). The mean TGW of the DH populations in six environments was used for correlation analysis, and the results showed highly significant positive correlations (Table S6). The heritability value for TGW in these populations was 0.59 (Table 2). 
Table 2. Value of thousand-grain weight (TGW) (g) trait in parents and the doubled haploid (DH) lines across all environments.

\begin{tabular}{|c|c|c|c|c|c|c|c|c|c|c|c|}
\hline \multirow{2}{*}{ Environment } & \multicolumn{2}{|c|}{ Parents } & \multicolumn{8}{|c|}{ DH Lines } & \multirow[b]{2}{*}{$h^{2}$} \\
\hline & $\mathrm{S}$ & $\mathbf{M}$ & Range & Min. & Max. & Mean & SD & CV (\%) & Sk. & Ku. & \\
\hline HX2015 & 48.23 & 39.18 & 19.72 & 32.20 & 51.95 & 40.59 & 4.46 & 19.93 & 0.056 & -0.631 & \multirow{6}{*}{0.59} \\
\hline HD2016 & 48.39 & 39.90 & 21.54 & 30.90 & 52.44 & 43.71 & 4.33 & 18.78 & -0.178 & -0.175 & \\
\hline XN2016 & 46.64 & 38.46 & 20.37 & 30.11 & 50.48 & 41.54 & 4.18 & 17.45 & -0.461 & -0.026 & \\
\hline HD2017 & 48.30 & 40.07 & 20.88 & 30.00 & 50.88 & 42.04 & 4.17 & 17.35 & -0.150 & -0.112 & \\
\hline XN2017 & 44.78 & 36.49 & 20.02 & 31.08 & 51.10 & 41.09 & 5.04 & 25.44 & -0.070 & -0.785 & \\
\hline HX2017 & 48.08 & 38.46 & 18.78 & 31.70 & 50.48 & 41.85 & 4.28 & 18.28 & -0.345 & -0.466 & \\
\hline
\end{tabular}

S, "Superb"; M, "M321"; SD, standard deviation; CV, coefficient of variation; Sk., skewness; Ku., kurtosis; and $\mathrm{h}^{2}$, heritability.

\subsection{QTL Analysis for TGW}

The biparental populations (BIP) function of IciMapping with the inclusive composite interval mapping (ICIM) module was applied to analyze the TGW trait of the DH population. After a 1000-times permutation test, the LOD (likelihood of odds) threshold was determined to be 3.22. Nine QTLs were detected in six environments, and they were mapped on chromosomes 1A, 2D, 4B, 4D, 5A, 5D, $6 \mathrm{~A}$, and 6D (Figure 2 and Table 3). The LOD values of each QTL ranged from 3.29 to 12.19 , and the additive effect ranged from -2.139 to 2.605 . The phenotypic variation explained by these QTLs ranged from $6.81 \%$ to $32.43 \%$. Considering the physical locations of the SNPs, these QTLs were named qTgw.nwipb-1AS, qTgw.nwipb-2DS, qTgw.nwipb-2DL, qTgw.nwipb-4BS, qTgw.nwipb-4DS, qTgw.nwipb-5AL, qTgw.nwipb-5DS, qTgw.nwipb-6AL, and qTgw.nwipb-6DS. Among these QTLs, qTgw.nwipb-4DS and $q T g w . n w i p b-6 A L$ could be detected in multiple environments in different years.

Interestingly, $q$ Tgw.nwipb-4DS and $q$ Tgw.nwipb-6AL explained $15.31 \%-32.43 \%$ and $21.34 \%-29.46 \%$ of the observed phenotypic variation, respectively, and both of them exhibited a relatively high LOD value in every environment, indicating that they were stable and robust QTLs. qTgw.nwipb-4DS was located in the interval of AX-95683531-AX-108924542, within a 2.609-cM genetic distance from $7.652 \mathrm{cM}$ to $10.261 \mathrm{cM}$, and $q T g w . n w i p b-6 A L$ was located in AX-108982634-AX-110577250, within a 5.256-cM region from $62.382 \mathrm{cM}$ to $67.638 \mathrm{cM}$. The additive effect was positive in $q T$ Tgw.nwipb-4DS, indicating that the alleles from M321 increased the TGW, while negative in $q T g w$.nwipb-6AL, demonstrating that the Superb alleles enhanced the TGW.

A combined QTL-by-environment interaction analysis performed with the multienvironmental trials (MET) module and the LOD threshold value of 6.23, seven QTLs were identified and mapped then to chromosomes 1A, 2D, 4B, 4D, 5A, 6A, and 6D (Figure 2 and Table 4). The two stable QTLs described above were also found to be robust in this module. The LOD values for $q T g w . n w i p b-4 D S$ and qTgw.nwipb-6AL were 33.73 and 36.99, respectively, and the $L O D(A)$ and $\operatorname{LDD}(\mathrm{AE})$ values were 26.70 and 7.03, respectively, for $q T g w . n w i p b-4 D S$ and 34.29 and 2.70 for $q T g w . n w i p b-6 A L$. Additionally, the PVE and PVE (AE) explained by $q T g w . n w i p b-4 D S$ were $22.24 \%$ and $4.57 \%$, respectively, while those explained by qTgw.nwipb-6AL were $26.96 \%$ and $3.41 \%$. The flanking markers of the QTLs were physically mapped on the chromosomes, these QTLs span $5.28 \mathrm{Mb}$ (1AS), $102.18 \mathrm{Mb}$ (2DS), $3.85 \mathrm{Mb}$ (4BS), $65.81 \mathrm{Mb}$ (4DS), $1.67 \mathrm{Mb}(5 \mathrm{AL}), 5.97 \mathrm{Mb}(6 \mathrm{AL})$, and $13.64 \mathrm{Mb}$ (6DS), respectively. Of them, these two stable QTLs span $65.81 \mathrm{Mb}(q T g w . n w i p b-4 D S)$ and $5.97 \mathrm{Mb}$ (qTgw.nwipb-6AL, located on the near-distal of chromosomes 4DS and 6AL, respectively (Table S3). 
1A

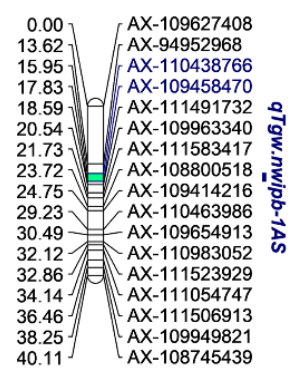

5A

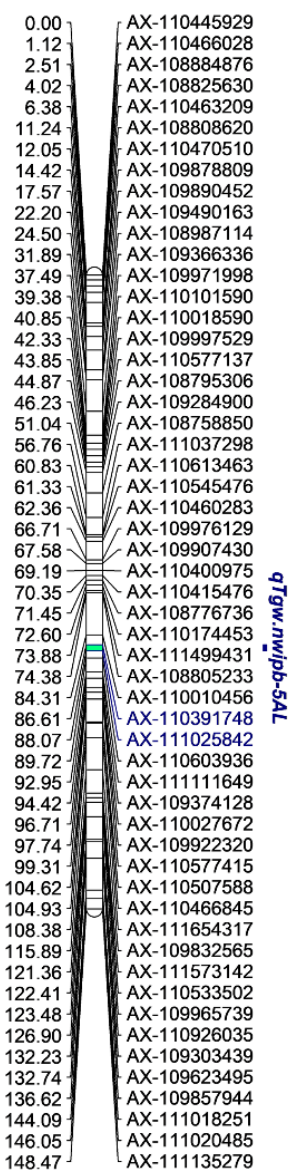

2D

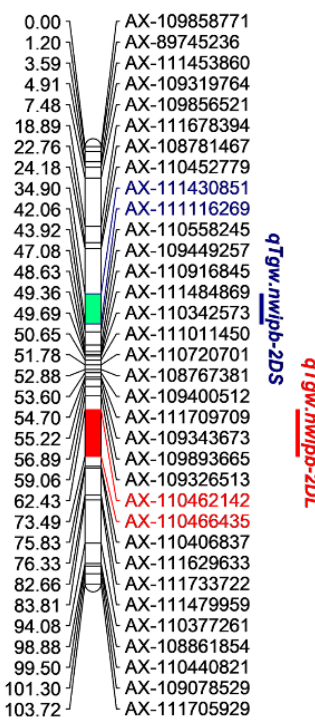

5D-1

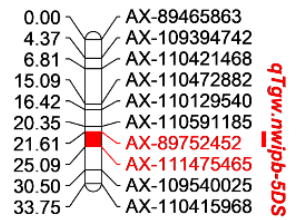

4B-1

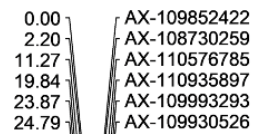
23.87 . AX-109993293 35.14 . AX-108731100 36.04 $=$ (AX-11011025 38.37 AX-111068079 41.14 H AX-109580651 41.93 AX-109955604 43.15 $=\begin{aligned} & \text { AX-111738217 } \\ & \text { AX-110097291 }\end{aligned}$ 44.52 $-\left[\begin{array}{l}\text { AX-110097291 } \\ \text { AX-109488 }\end{array}\right.$

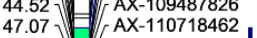
48.94 目 AX-111651544 $53.45)=\left(\begin{array}{l}A X-109037159 \\ A X-111477393\end{array}\right.$ 54.39 不 AX-94474747 57.84 目 61.15 AXX-110075169 63.30 AX-108806641 64.18 AX-111520953 65.76 AX-111160295 66.81 - AX-110967502 67.98 ) AX-94448564 69.32. 71.78 88.39 AX-111556599 89.55 AX-108776440 96.01 AX-111022978 $\left.\begin{array}{c}99.12 \\ 100.26\end{array}\right]\left[\begin{array}{l}\text { AX-109828571 } \\ \text { AX-109440160 }\end{array}\right.$

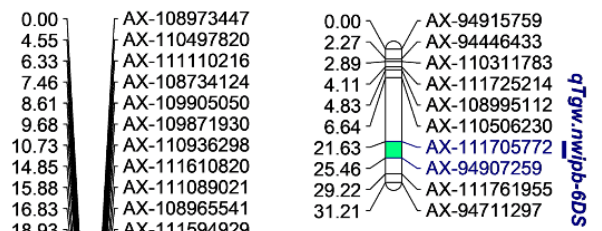

4D-2

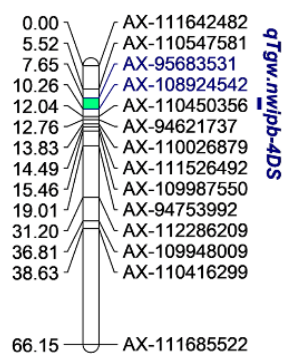

$66.15-A X-111685522$

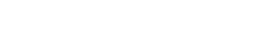

\section{A}

6D-1

AX-110905458

AX-109512342

AX-110991782 AX-110666660 AX-110947561 AX-108829497 4.81] $45.96]=$ AX-11090493 $49.00=\mathrm{AXX}_{\text {AX-111464624 }}$ 51.12 有 AX-109884190 을 52.51 AX-111101235 54.03 4 . 55.77 目 56.53 AX-109332464

56.94 AX-110018729

57.48 的 AX-109039220

58.41 A AX-111131762

67.64 - AX-110577250

70.28 AX-109295804

72.71 AX-109370898

74.98 AX-111134280

76.31 AX-109837110

84.19 AX-111195834

87.48 AX-110003081
AX-110072628

88.06 AX-110072628

$89.23 \quad$ AX-110101588

91.29 AX-110930450

94.19 AX-109552957

95.06
103.75 $\quad \begin{aligned} & A X-111049268 \\ & \text { AX-111562681 }\end{aligned}$

Figure 2. Quantitative trait locus (QTL) for 1000-grain weight trait of the doubled haploid (DH) population. Genetic distances are annotated on the left of each chromosome, and the markers names are annotated on the right. The QTLs with red color show that they were identified by the biparental populations (BIP) function, and those with purple color denote that they were detected by both the BIP function and multienvironmental trials (MET) function. 
Table 3. Quantitative trait locus (QTL) for the TGW traits in different environments.

\begin{tabular}{|c|c|c|c|c|c|c|c|c|c|c|}
\hline QTL & Pos.(cM) & Environment & Chr. & Interval (cM) & Flanking markers & LOD & Add & PVE (\%) & $\begin{array}{l}\text { Physical } \\
\text { pos. (Mb) }\end{array}$ & $\begin{array}{l}\text { Near Locus in } \\
\text { Previous Studies }\end{array}$ \\
\hline qTgw.nwipb-1AS & 16.890 & HD2017 & $1 \mathrm{~A}$ & $15.954-17.833$ & AX-110438766-AX-109458470 & 3.68 & -1.204 & 8.09 & $20.02-25.31$ & QGw.ccsu-1A.1 [5] \\
\hline qTgw.nwiph-2DS & 40.270 & DLH2015 & $2 \mathrm{D}$ & $34.900-42.060$ & AX-111430851-AX-111116269 & 4.98 & -1.698 & 14.54 & $243.79-345.97$ & \\
\hline qTgw.nwiph-2DL & 70.414 & XN2017 & $2 \mathrm{D}$ & $62.425-73.487$ & AX-110462142-AX-110466435 & 4.44 & -1.449 & 9.81 & 585.69-601.05 & \\
\hline qTgw.nwipb-4BS & 40.678 & DLH2017 & $4 \mathrm{~B}$ & $38.368-41.140$ & AX-111068079-AX-109580651 & 4.24 & 1.692 & 12.75 & $25.35-29.20$ & QTKW.caas-4BS [32] \\
\hline \multirow[t]{4}{*}{ qTgw.nwipb-4DS } & 8.956 & DLH2015 & $4 \mathrm{D}$ & $7.652-10.261$ & AX-95683531-AX-108924542 & 5.16 & 1.744 & 15.31 & $28.44-94.25$ & \\
\hline & & XN2016 & $4 \mathrm{D}$ & $7.652-10.261$ & AX-95683531-AX-108924542 & 5.12 & 1.789 & 17.17 & & \\
\hline & & HD2017 & $4 \mathrm{D}$ & $7.652-10.261$ & AX-95683531-AX-108924542 & 9.44 & 2.103 & 24.65 & & \\
\hline & & XN2017 & $4 \mathrm{D}$ & $7.652-10.261$ & AX-95683531-AX-108924542 & 12.19 & 2.605 & 32.43 & & \\
\hline qTgw.nwipb-5AL & 87.339 & XN2017 & $5 \mathrm{~A}$ & $86.608-88.069$ & AX-110391748-AX-111025842 & 3.38 & 1.235 & 6.97 & $594.37-596.03$ & QTKW.caas-5AL [32. \\
\hline qTgw.nwiph-5DS & 22.651 & HD2016 & $5 \mathrm{D}$ & $21.606-25.089$ & AX-89752452-AX-111475465 & 3.59 & 1.415 & 13.16 & $41.82-44.93$ & \\
\hline \multirow[t]{5}{*}{ qTgw.nwipb-6AL } & 64.353 & DLH2015 & $6 \mathrm{~A}$ & $62.382-67.638$ & AX-108982634-AX-110577250 & 7.18 & -2.113 & 22.43 & $573.48-579.45$ & \\
\hline & & XN2016 & $6 \mathrm{~A}$ & $62.382-67.638$ & AX-108982634-AX-110577250 & 6.91 & -2.139 & 24.44 & & \\
\hline & & HD2016 & $6 \mathrm{~A}$ & $62.382-67.638$ & AX-108982634-AX-110577250 & 7.38 & -2.119 & 29.46 & & \\
\hline & & DLH2017 & $6 \mathrm{~A}$ & $62.382-67.638$ & AX-108982634-AX-110577250 & 7.61 & -2.404 & 25.97 & & \\
\hline & & HD2017 & $6 \mathrm{~A}$ & $62.382-67.638$ & AX-108982634-AX-110577250 & 8.41 & -1.956 & 21.34 & & \\
\hline qTgw.nwipb-6DS & 23.301 & XN2017 & $6 \mathrm{D}$ & $21.626-25.455$ & AX-111705772-AX-94907259 & 3.29 & -1.195 & 6.81 & $10.91-24.55$ & \\
\hline
\end{tabular}

Pos., position; Chr., chromosome; Add, additive effect-positive values indicate that M321 alleles increased the TGW trait, and negative values indicate that the Superb alleles increased it; LOD, likelihood of odds; and PVE (\%), proportion of phenotypic variation of the corresponding QTL. 
Table 4. QTL analysis for TGW from multienvironmental trials (MET).

\begin{tabular}{cccccccccc}
\hline QTL & Chr. & Interval (cM) & LOD & $\begin{array}{c}\text { LOD } \\
\text { (A) }\end{array}$ & $\begin{array}{c}\text { LOD } \\
\text { (AE) }\end{array}$ & PVE & $\begin{array}{c}\text { PVE } \\
\text { (A) }\end{array}$ & $\begin{array}{c}\text { PVE } \\
\text { (AE) }\end{array}$ & Add \\
\hline qTgw.nwipb-1AS & 1A & $15.954-17.833$ & 9.06 & 7.97 & 1.09 & 5.02 & 4.62 & 0.40 & -0.792 \\
qTgw.nwipb-2DS & 2D & $34.900-42.060$ & 9.11 & 7.01 & 2.11 & 6.06 & 4.15 & 1.90 & -0.753 \\
qTgw.nwipb-4BS & 4B & $38.368-41.140$ & 6.69 & 3.66 & 3.04 & 4.82 & 2.14 & 2.68 & 0.545 \\
qTgw.nwipb-4DS & 4D & $7.652-10.261$ & 33.73 & 26.70 & 7.03 & 22.24 & 17.66 & 4.57 & 1.551 \\
qTgw.nwipb-5AL & 5A & $86.608-88.069$ & 10.92 & 10.20 & 0.71 & 6.06 & 5.86 & 0.20 & 0.914 \\
qTgw.nwipb-6AL & 6A & $62.382-67.638$ & 36.99 & 34.29 & 2.70 & 26.96 & 23.55 & 3.41 & -1.795 \\
qTgw.nwipb-6DS & 6D & $21.626-25.455$ & 6.67 & 5.67 & 1.00 & 3.81 & 3.28 & 0.53 & -0.669 \\
\hline
\end{tabular}

LOD (A) and LOD (AE): indicate the LOD value for additive and dominance effects and LOD score for additive and dominance by environment effects, respectively. PVE (A) and PVE (AE) represent the phenotypic variation explained by additive and dominance effects and additive and dominance by environment effects, separately.

\section{Discussion}

Grain yield is the most important trait in wheat-breeding programs, which was a continuous variation trait controlled by multiple quantitative trait loci [33]. Most of grain yield-related traits, such as the flowering period, and biological, as well as abiotic, resistance, are controlled by many genes with low heritability. TGW is an important component of grain yield, which is a high-heritability yield trait, and the influence of the environment on it is significantly lower or even insensitive than other yield-related traits [34]. TGW is often positively correlated with the crop yield [3], indicating that it is possible to indirectly improve 1000-grain weight to increase the grain yield. To meet the increasing demand for wheat production, an increasing number of valuable TGW genes (QTLs) should be identified to increase the wheat yield.

In this study, seven QTLs of the TGW trait were identified in six environments, six of which were located in genomes $\mathrm{A}$ and $\mathrm{D}$ and explained more than $70 \%$ of the observed phenotypic variation. qTgw.nwipb-4DS and qTgw.nwipb-6AL were detected in more than four environments. qTgw.nwipb-6AL was expressed in five environments, with the exception of XN2017. Continuous rainfall from June to September 2017 caused some of the DH lines to undergo preharvest sprouting in Xining, causing the 1000-grain weight data distribution to deviate from those in the other experimental environments, which might be the main reason why $q$ Tgw.nwipb-6AL was not detected in XN2017.

PVE is the sum of the PVE (A) and PVE (AE). The PVE (A) and PVE (AE) values of these QTLs ranged from 2.14 to 23.55 and 0.20 to 4.57 , respectively (Table 4). The values of the PVE (AE) were much lower than those of the PVE (A), indicating that the QTLs were less affected by environmental factors and implying that $q T g w . n w i p b-4 D S$ and $q T g w . n w i p b-6 A L$ were stable QTLs.

In this research, $q T g w . n w i p b-4 D S$ and $q T g w . n w i p b-6 A L$ were identified, and both were found to be major effective and robust QTLs; approximately $50 \%$ of the observed phenotypic variation was explained by these two QTLs together. Several QTLs in wheat have been reported to be effective for TGW improvement [34], although they have rarely been reported located on chromosome 6A compared with the other chromosomes $[16,18,35]$. By using a recombinant inbred line (RIL) population, Su et al. (2011) fine-mapped the gene TaGW2-6A (genomic location from 237,735,006 bp to 237,759,304 bp) near the centromere of $6 \mathrm{~A}$ [21]. In our work, $q T$ Tgw.nwipb-6AL was found to be physically mapped between $573,480,239 \mathrm{bp}$ and $579,446,410 \mathrm{bp}$ on the end of $6 \mathrm{AL}$, and we conclude that it is likely to be a novel QTL with a high LOD and PVE.

In rice, the RING-type E3 ubiquitin ligase OsGW2 has been shown to negatively affect the grain width. The wheat homologue TaGW2 has been mapped to chromosome 6A. The interval of qTgw.nwipb-6AL contains 71 predicted genes based on IWGSC RefSeq v1.0 (Table S7). Among the 71 genes, TraesCS6A01G343600 encodes the E3 ubiquitin-protein ligase (from 577,780,417 bp to $577,781,984 \mathrm{bp}$ ). Therefore, it may be considered as a potential candidate gene for $q T g w . n w i p b-6 A L$.

The flanking markers of the QTLs detected on the genetic maps in the current study were mostly consistent with their corresponding positions on the chromosomes. The additive effect was positive 
in $q T g w . n w i p b-4 D S$, indicating that the alleles from M321 increased the TGW. However, the flanking physical positions for the flanking markers of $q T g w . n w i p b-4 D S$ were $28,448,472 \mathrm{bp}$ and $94,254,122 \mathrm{bp}$ on the short arm of $4 \mathrm{D}$. It was spanned $65.81 \mathrm{Mb}$, with only 2.609-cM genetic distance. We preliminarily inferred that chromosome fragment translocation might be occurring during distant hybridization. M321 is a wheat line derived from Superb/Triticum monococcum//Fukuho. T. monococcum was the donor of the $\mathrm{A}^{\mathrm{m}}$ genome. Fukuho is a Japanese wheat cultivar with an AABBDD genome. Parental hybrids producing $\mathrm{F}_{1}$ plants with different ploidies will produce unequal numbers of univalent bodies during meiosis, leading to chromosome segregation disorders [36]. Translocation might have occurred on chromosomes $4 \mathrm{D}$ during the development process of M321, resulting in the variation that was retained in the DH population. Future work should be carried out to confirm the chromosomal structural variation of $4 \mathrm{D}$ in M321 and identify the candidate genes of the two major effective QTLs.

\section{Materials and Methods}

\subsection{Plant Materials}

A doubled haploid (DH) population including 85 lines derived from a cross between "Superb" and "M321" and was produced by the maize pollination method. "Superb" is a Canadian Western red spring cultivar with a relatively high harvest yield and thousand-grain weight (TGW) and multiple tillers [37-39]. Fukuho-Komugi is a Japanese spring cultivar. T. monococcum $\left(\mathrm{A}^{\mathrm{m}} \mathrm{A}^{\mathrm{m}}\right)$ 10-1 is the $\mathrm{A}^{\mathrm{m}}$ genome donor. M321 is a spring wheat line derived from a Superb/T. monococcum 10-1/Fukuho-Komugi cross with a low thousand-grain weight (TGW); it was developed by Dr. George Fedak in the 1990s.

The DH population and its parents were planted in Delingha (DLH) in the Haixi Mongol and Tibetan Autonomous Prefecture, Qinghai Province $\left(97.37^{\circ}\right.$ E, $37.37^{\circ}$ N) (2015 and 2017), Liming Village in Haidong (HD) City, Qinghai Province (102.09 E, 36.47 $\left.{ }^{\circ} \mathrm{N}\right)(2016$ and 2017), and Changning Village in Xining (XN) City, Qinghai Province $\left(101.74^{\circ} \mathrm{E}, 36.56^{\circ} \mathrm{N}\right)(2016$ and 2017). Each DH line and the parents were in a single 2-meter row with $0.2 \mathrm{~m}$ between rows, and the sowing density was 100 seeds per row. Nitrogen and superphosphate fertilizers were applied at a rate of 80 and $100 \mathrm{~kg} / \mathrm{ha}$, respectively, at sowing. Field management was performed according to the common practices. Thousand-grain weight (TGW) was evaluated by weighing 1000 kernels with precision of $0.01 \mathrm{~g}$ in the laboratory after harvest. TGW data were statistically analyzed using SPSS 18.0.

\subsection{Molecular Genotyping and Genetic Linkage Map Construction}

The two parents and each DH line of the population were sprouted in dishes for 2 weeks, and genomic DNA was extracted from young leaves using the Plant Genomic DNA Kit (TIANGEN Biotech, Beijing, China). A total of $1 \mu \mathrm{L}$ of DNA solution was used to check the DNA quality in $10-\mathrm{g} / \mathrm{L}$ agarose gels by electrophoresis, and the DNA concentration was measured with a NanoDrop 2000 C spectrophotometer (Thermo Scientific, Wilmington, DE, USA). The DNA of the DH population was genotyped with the 55-k iSelect single-nucleotide polymorphism (SNP) genotyping assay, which contains 53,063 markers (CaptialBio Technology, Beijing, China).

The SNP data were considered to be missing data if they were heterozygous. The markers that were identical in the two parents were rejected and then converted to SNP data in the format required by IciMapping 4.1 [40]. The BIN function of IciMapping 4.1 was used to filter the SNP markers by removing the data exhibiting more than $10 \%$ missing data and a distortion value of less than 0.01 . Each bin included no less than one marker. A Bin ID value - 1 indicated that a marker had been deleted, and a positive value indicated that markers had been retained. Then, markers were selected according to the lowest missing rate from each bin. By using JoinMap 4.0, the markers were ordered into corresponding groups with LOD scores ranging from 2 to 10, and each group was then used to construct a linkage map by using the Kosambi mapping function with an LOD $\geq 5$ [20,41]. To obtain the physical locations of the SNPs and divide the long and short chromosome arms of the genetic map, the flanking sequences were subjected to BLAST searches with the IWGSC wheat contig sequences 
(http://www.wheatgenome.org/). All of the genetic maps generated in the present study were drawn by using Mapchart 2.0 [42].

\subsection{Statistical Analysis and QTL Mapping}

The TGW phenotypic data from each environment were statistically analyzed using SPSS 18.0. The formula used to compute heritability was derived from $\mathrm{Hu}$ et al. (2017) [43]. IciMapping 4.1 was used for QTL analysis. The QTLs for TGW from every environment were detected in the biparental populations (BIP), in which an inclusive composite interval mapping (ICIM) module with an LOD score value over 3.0 was used. QTLs and environmental interactions were studied in multienvironment trials (METs). The mapping parameters were set as follows: QTL walking speed of $1.00 \mathrm{cM}$, stepwise regression probability threshold value of 0.001 , and the threshold LOD was determined by permutation tests $($ Times $=1000$ and Type I Error $=0.05$ ). The international customary rule was applied to nominate QTLs. "Tgw", "nwipb", "L", and "S" represent the "thousand-grain weight", "Northwest Institute of Plateau Biology, CAS", the "long arm of the chromosome", and the "short arm of the chromosome", respectively.

\section{Conclusions}

In summary, nine TGW QTLs were identified in this study, including the major and robust novel loci $q T g w . n w i p b-4 D S$ and $q T g w . n w i p b-6 A L$, with genetic distances of $2.609 \mathrm{cM}$ and $5.256 \mathrm{cM}$, respectively. TraesCS6A01G343600 encodes the E3 ubiquitin-protein ligase; it may be considered as a potential candidate gene for $q$ Tgw.nwipb-6AL. These two novel QTLs may be used in marker-assisted selections in wheat high-yield breeding. Our findings provided new data on QTLs related to thousand-grain weight in wheat and will enhance the understanding of the genetic basis of TGW traits.

Supplementary Materials: Supplementary materials can be found at http://www.mdpi.com/1422-0067/21/11/ 3960/s1.

Author Contributions: H.Z. and B.Z. designed the study. T.L. and L.W. conducted the experiments and analyzed the data. T.L. drafted the manuscript. D.C. and G.F. constructed the DH population. X.G., W.C. (Wenjie Chen), B.L., D.L., and W.C. (Wenguang Cao) critically reviewed and improved the manuscript. All authors have read and approved the final version of the manuscript.

Funding: This research was funded by the Project from Qinghai Province (2016-HZ-808 and 2020-HZ-807), STS Project of Chinese Academy of Sciences (KFJ-STS-ZDTP-024CAS), STS Project of Chinese Academy of Sciences (KFJ-STS-ZDTP-056-2), and the Program of Science and Technology Innovation Platform of Qinghai Province (2017-ZJ-Y14).

Conflicts of Interest: The authors declare no conflicts of interest.

\section{Abbreviations}

$\begin{array}{ll}\text { TGW } & \text { Thousand-grain weight } \\ \text { QTL } & \text { Quantitative trait locus } \\ \text { DH population } & \text { Double haploid population } \\ \text { SNP } & \text { Single-nucleotide polymorphisms }\end{array}$

\section{References}

1. United Nations, Department of Economic Population Division. Population Division, World Population Prospects: The 2017 Revision, Key Findings and Advance Tables; ESA/P/WP/248; United Nations: Rome, Italy, 2017.

2. Brinton, J.; Simmonds, J.; Minter, F.; Leverington-Waite, M.; Snape, J.; Uauy, C. Increased pericarp cell length underlies a major quantitative trait locus for grain weight in hexaploid wheat. New Phytol. 2017, 215, 1026-1038. [CrossRef] [PubMed]

3. Mengistu, N.; Baenziger, P.S.; Eskridge, K.M.; Dweikat, I.; Wegulo, S.N.; Gill, K.S.; Mujeeb-Kazi, A. Validation of QTL for Grain Yield-Related Traits on Wheat Chromosome 3A Using Recombinant Inbred Chromosome Lines. Crop Sci. 2012, 52, 1622-1632. [CrossRef] 
4. Kuchel, H.; Williams, K.J.; Langridge, P.; Eagles, H.A.; Jefferies, S.P. Genetic dissection of grain yield in bread wheat. I. QTL analysis. Theor. Appl. Genet. 2007, 115, 1029-1041. [CrossRef] [PubMed]

5. Kumar, N.; Kulwal, P.L.; Gaur, A.; Tyagi, A.K.; Khurana, J.P.; Khurana, P.; Balyan, H.S.; Gupta, P.K. QTL analysis for grain weight in common wheat. Euphytica 2006, 151, 135-144. [CrossRef]

6. Varshney, R.K.; Prasad, M.; Roy, J.K.; Harjit-Singh, N.K.; Dhaliwal, H.S.; Balyan, H.S.; Gupta, P.K. Identification of eight chromosomes and a microsatellite marker on 1AS associated with QTL for grain weight in bread wheat. Theor. Appl. Genet. 2000, 1000, 1290-1294. [CrossRef]

7. Narasimhamoorthy, B.; Gill, B.S.; Fritz, A.K.; Nelson, J.C.; Brown-Guedira, G.L. Advanced backcross QTL analysis of a hard winter wheat $x$ synthetic wheat population. Theor. Appl. Genet. 2006, 112, 787-796. [CrossRef]

8. McCartney, C.A.; Somers, D.J.; Humphreys, D.G.; Lukow, O.; Ames, N.; Noll, J.; Cloutier, S.; McCallum, B.D. Mapping quantitative trait loci controlling agronomic traits in the spring wheat cross RL4452x 'AC Domain'. Genome 2005, 48, 870-883. [CrossRef]

9. Quarrie, S.A.; Steed, A.; Calestani, C.; Semikhodskii, A.; Lebreton, C.; Chinoy, C.; Steele, N.; Pljevljakusic, D.; Waterman, E.; Weyen, J.; et al. A high-density genetic map of hexaploid wheat (Triticum aestivum L.) from the cross Chinese Spring x SQ1 and its use to compare QTLs for grain yield across a range of environments. Theor. Appl. Genet. 2005, 110, 865-880. [CrossRef]

10. Campbell, K.G.; Bergman, C.J.; Gualberto, D.G.; Anderson, J.A.; Giroux, M.J.; Hareland, G.; Fulcher, R.G.; Sorrells, M.E.; Finney, P.L. Quantitative Trait Loci Associated with Kernel Traits in a Soft Hard Wheat Cross. Crop Sci. 1999, 39, 1184-1195. [CrossRef]

11. Huang, X.Q.; Coster, H.; Ganal, M.W.; Roder, M.S. Advanced backcross QTL analysis for the identification of quantitative trait loci alleles from wild relatives of wheat (Triticum aestivum L.). Theor. Appl. Genet. 2003, 106, 1379-1389. [CrossRef]

12. Ramya, P.; Chaubal, A.; Kulkarni, K.; Gupta, L.; Kadoo, N.; Dhaliwal, H.S.; Chhuneja, P.; Lagu, M.; Gupt, V. QTL mapping of 1000-kernel weight, kernel length, and kernel width in bread wheat (Triticum aestivum L.). J. Appl. Genet. 2010, 51, 421-429. [CrossRef] [PubMed]

13. Li, S.; Jia, J.; Wei, X. y.; Zhang, X.; Li, L.; Chen, H.; Fan, Y.; Sun, H.; Zhao, X.; Lei, T.; et al. A intervarietal genetic map and QTL analysis for yield traits in wheat. Mol. Breed. 2007, 20, 167-178. [CrossRef]

14. Marza, F.; Bai, G.H.; Carver, B.F.; Zhou, W.C. Quantitative trait loci for yield and related traits in the wheat population Ning7840 x Clark. Theor. Appl. Genet. 2006, 112, 688-698. [CrossRef] [PubMed]

15. Liu, G.; Jia, L.; Lu, L.; Qin, D.; Zhang, J.; Guan, P.; Ni, Z.; Yao, Y.; Sun, Q.; Peng, H. Mapping QTLs of yield-related traits using RIL population derived from common wheat and Tibetan semi-wild wheat. Theor. Appl. Genet. 2014, 127, 2415-2432. [CrossRef]

16. Roder, M.S.; Huang, X.Q.; Borner, A. Fine mapping of the region on wheat chromosome 7D controlling grain weight. Funct. Integr. Genom. 2008, 8, 79-86. [CrossRef]

17. Sun, X.-Y.; Wu, K.; Zhao, Y.; Kong, F.-M.; Han, G.-Z.; Jiang, H.-M.; Huang, X.-J.; Li, R.-J.; Wang, H.-G.; Li, S.-S. QTL analysis of kernel shape and weight using recombinant inbred lines in wheat. Euphytica 2009, 165, 165:615. [CrossRef]

18. Simmonds, J.; Scott, P.; Leverington-Waite, M.; Turner, A.S.; Brinton, J.; Korzun, V.; Snape, J.; Uauy, C. Identification and independent validation of a stable yield and thousand grain weight QTL on chromosome 6A of hexaploid wheat (Triticum aestivum L.). BMC Plant Biol. 2014, 14, 191. [CrossRef]

19. Zanke, C.D.; Ling, J.; Plieske, J.; Kollers, S.; Ebmeyer, E.; Korzun, V.; Argillier, O.; Stiewe, G.; Hinze, M.; Neumann, F.; et al. Analysis of main effect QTL for thousand grain weight in European winter wheat (Triticum aestivum L.) by genome-wide association mapping. Front. Plant Sci. 2015, 6, 644. [CrossRef]

20. Liu, J.; Luo, W.; Qin, N.; Ding, P.; Zhang, H.; Yang, C.; Mu, Y.; Tang, H.; Liu, Y.; Li, W.; et al. A 55 K SNP array-based genetic map and its utilization in QTL mapping for productive tiller number in common wheat. Theor. Appl. Genet. 2018, 131, 2439-2450. [CrossRef]

21. Su, Z.; Hao, C.; Wang, L.; Dong, Y.; Zhang, X. Identification and development of a functional marker of TaGW2 associated with grain weight in bread wheat (Triticum aestivum L.). Theor. Appl. Genet. 2011, 122, 211-223. [CrossRef] 
22. Sajjad, M.; Ma, X.; Habibullah Khan, S.; Shoaib, M.; Song, Y.; Yang, W.; Zhang, A.; Liu, D. TaFlo2-A1, an ortholog of rice Flo2, is associated with thousand grain weight in bread wheat (Triticum aestivum L.). BMC Plant Biol. 2017, 17, 164. [CrossRef] [PubMed]

23. Cui, F.; Zhang, N.; Fan, X.L.; Zhang, W.; Zhao, C.H.; Yang, L.J.; Pan, R.Q.; Chen, M.; Han, J.; Zhao, X.Q.; et al. Utilization of a Wheat660K SNP array-derived high-density genetic map for high-resolution mapping of a major QTL for kernel number. Sci. Rep. 2017, 7, 3788. [CrossRef] [PubMed]

24. Somers, D.J.; Isaac, P.; Edwards, K. A high-density microsatellite consensus map for bread wheat (Triticum aestivum L.). Theor. Appl. Genet. 2004, 109, 1105-1114. [CrossRef] [PubMed]

25. Seeb, J.E.; Carvalho, G.; Hauser, L.; Naish, K.; Roberts, S.; Seeb, L.W. Single-nucleotide polymorphism (SNP) discovery and applications of SNP genotyping in nonmodel organisms. Mol. Ecol. Resour. 2011, 11 (Suppl. 1), 1-8. [CrossRef]

26. Huang, X.; Wei, X.; Sang, T.; Zhao, Q.; Feng, Q.; Zhao, Y.; Li, C.; Zhu, C.; Lu, T.; Zhang, Z.; et al. Genome-wide association studies of 14 agronomic traits in rice landraces. Nat. Genet. 2010, 42, 961-967. [CrossRef]

27. Palaisa, K.A.; Morgante, M.; Williams, M.; Rafalski, A. Contrasting effects of selection on sequence diversity and linkage disequilibrium at two phytoene synthase loci. Plant Cell 2003, 15, 1795-1806. [CrossRef]

28. Cavanagh, C.R.; Chao, S.; Wang, S.; Huang, B.E.; Stephen, S.; Kiani, S.; Forrest, K.; Saintenac, C.; Brown-Guedira, G.L.; Akhunova, A.; et al. Genome-wide comparative diversity uncovers multiple targets of selection for improvement in hexaploid wheat landraces and cultivars. Proc. Natl. Acad. Sci. USA 2013, 110, 8057-8062. [CrossRef]

29. Wang, S.; Wong, D.; Forrest, K.; Allen, A.; Chao, S.; Huang, B.E.; Maccaferri, M.; Salvi, S.; Milner, S.G.; Cattivelli, L.; et al. Characterization of polyploid wheat genomic diversity using a high-density 90,000 single nucleotide polymorphism array. Plant Biotechnol. J. 2014, 12, 787-796. [CrossRef]

30. Winfield, M.O.; Allen, A.M.; Burridge, A.J.; Barker, G.L.; Benbow, H.R.; Wilkinson, P.A.; Coghill, J.; Waterfall, C.; Davassi, A.; Scopes, G.; et al. High-density SNP genotyping array for hexaploid wheat and its secondary and tertiary gene pool. Plant Biotechnol. J. 2016, 14, 1195-1206. [CrossRef]

31. Ren, T.; Hu, Y.; Tang, Y.; Li, C.; Yan, B.; Ren, Z.; Tan, F.; Tang, Z.; Fu, S.; Li, Z. Utilization of a Wheat55K SNP Array for Mapping of Major QTL for Temporal Expression of the Tiller Number. Front. Plant Sci. 2018, 9, 333. [CrossRef]

32. Li, F.; Wen, W.; He, Z.; Liu, J.; Jin, H.; Cao, S.; Geng, H.; Yan, J.; Zhang, P.; Wan, Y.; et al. Genome-wide linkage mapping of yield-related traits in three Chinese bread wheat populations using high-density SNP markers. Theor. Appl. Genet. 2018, 131, 1903-1924. [CrossRef] [PubMed]

33. Heidari, B.; Sayed-Tabatabaei, B.E.; Saeidi, G.; Kearsey, M.; Suenaga, K. Mapping QTL for grain yield, yield components, and spike features in a doubled haploid population of bread wheat. Genome 2011, 54, 517-527. [CrossRef] [PubMed]

34. Liu, W.; Leiser, W.L.; Reif, J.C.; Tucker, M.R.; Losert, D.; Weissmann, S.; Hahn, V.; Maurer, H.P.; Würschum, T. Multiple-line cross QTL mapping for grain yield and thousand kernel weight in triticale. Plant Breed. 2016. [CrossRef]

35. Lee, H.S.; Jung, J.-U.; Kang, C.-S.; Heo, H.-Y.; Park, C.S. Mapping of QTL for yield and its related traits in a doubled haploid population of Korean wheat. Plant Biotechnol. Rep. 2014, 8, 443-454. [CrossRef]

36. Zhang, Y.; Wang, L. Cytological Studies on Interspecific Hybrids of Different Ploidy Wheat. J. Henan Agric. Sci. 2011, 40, 14-17.

37. Randhawa, H.; Puchalski, B.J.; Frick, M.; Goyal, A.; Despins, T.; Graf, R.J.; Laroche, A.; Gaudet, D.A. Stripe rust resistance among western Canadian spring wheat and triticale varieties. Can. J. Plant Sci. 2012, 92, 713-722. [CrossRef]

38. DePauw, R.M.; Knox, R.E.; McCaig, T.N.; Clarke, F.R.; Clarke, J.M. Carberry hard red spring wheat. Can. J. Plant Sci. 2011, 91, 529-534. [CrossRef]

39. DePauw, R.M.; Townley-Smith, T.F.; Humphreys, G.; Knox, R.E.; Clarke, F.R.; Clarke, J.M. Lillian hard red spring wheat. Can. J. Plant Sci. 2005, 85, 397-401. [CrossRef]

40. Meng, L.; Li, H.; Zhang, L.; Wang, J. QTL IciMapping: Integrated software for genetic linkage map construction and quantitative trait locus mapping in biparental populations. Crop J. 2015, 3, 269-283. [CrossRef] 
41. Chang, Y.; Oh, E.U.; Lee, M.S.; Kim, H.B.; Moon, D.-G.; Song, K.J. Construction of a genetic linkage map based on RAPD, AFLP, and SSR markers for tea plant (Camellia sinensis). Euphytica 2017, 213, 190. [CrossRef]

42. Voorrips, R.E. MapChart: Software for the graphical presentation of linkage maps and QTLs. J. Hered. 2002, 93, 77-78. [CrossRef] [PubMed]

43. Hu, Y.S.; Ren, T.H.; Li, Z.; Tang, Y.Z.; Ren, Z.L.; Yan, B.J. Molecular mapping and genetic analysis of a QTL controlling spike formation rate and tiller number in wheat. Gene 2017, 634, 15-21. [CrossRef] [PubMed]

(C) 2020 by the authors. Licensee MDPI, Basel, Switzerland. This article is an open access article distributed under the terms and conditions of the Creative Commons Attribution (CC BY) license (http://creativecommons.org/licenses/by/4.0/). 